\title{
Generalized eruptive keratoacanthoma
}

INSERM

\section{Source}

INSERM. (1999). Orphanet: an online rare disease and orphan drug data base.

Generalized eruptive keratoacanthoma. ORPHA:411777

Generalized eruptive keratoacanthoma (GEKA) is rare variant of keratoacanthoma (KA) that affects the skin and mucous membranes and which is characterized by a sudden generalized eruption of severely pruritic, hundreds to thousands of small follicular papules, often with a central keratotic plug. 